\title{
TRADUÇÃO ROMANA: SUPLANTAÇÃO DO MODELO ${ }^{1}$
}

Mauri Furlan*

Universidade Federal de Santa Catarina/ Procad-Capes-UFMG

\begin{abstract}
The historical, political and cultural context of Ancient Rome generated a conception of writing, and, as a consequence, a conception of translation - moulded in classical rhetoric and identified in its operating system inuentio-elocutio - that characterizes the translation mode practiced at that time as supplanter of its model by reinventing, appropriating, and latinizing the Greek source.
\end{abstract}

KEYWORDS: Roman translation; translation conception; classical rhetoric; inuentio-elocutio; Cicero.

6

erto tipo de traduções realizadas em Roma no século I a.C. século do auge do Império Romano, com os maiores expoentes de sua cultura no âmbito literário, político, social etc - constituiu um padrão que acabou por caracterizar a prática tradutória dos romanos em geral. Afirmá-lo não significa dizer que aquela sociedade não tenha produzido distintos tipos de tradução. Mas o que caracteriza a principal forma de tradução romana?

Qualquer análise sobre determinado fato social não pode desconsiderar o momento histórico, fatores e conjunturas implicados na produção do fato. A tradução é uma prática histórica e linguística e participa de uma concepção histórica de linguagem. Investigar concepção

\footnotetext{
^maurizius@gmail.com

${ }^{1}$ Texto originalmente apresentado como palestra proferida nas Jornadas Saber e Poder, do Núcleo de Estudos Antigos e Medievais, NEAM-FALE-UFMG, em 12 de novembro de 2010, Belo Horizonte- MG.
} 
e prática da tradução significa investigar a teoria da linguagem que lhe é subjacente, a qual se expressa mediante códigos. Sabemos que a concepção de linguagem presente na Grécia e Roma clássicas se plasmou, enquanto teoria, no código que conhecemos como retórica clássica, e que esse código perviveu praticamente até o século XVIII. Mas sabemos também que em distintos períodos da história da humanidade e do pensamento Ocidental, a prática da escrita e, por conseguinte, da tradução revelam-se em formas e estilos muito diferenciados entre si, pelo que devemos supor que algo nesse código que plasmou a concepção da linguagem da Antiguidade ao século XVIII transformou-se e produziu as diferenças e características de cada momento histórico. Tais mudanças, por sua vez, podem ser explicadas mediante o conhecimento do sistema operador da retórica clássica em cada período. Nomeamos esses possíveis sistemas operadores a partir das três principais partes da retórica: inuentio, dispositio e elocutio. Sempre vale relembrar, ainda que sucintamente, a ideia básica de cada uma dessas partes.

A primeira parte de um tratado de retórica era dedicada à inuentio, cujo objetivo era inuenire quid dicere, encontrar o que dizer. A preocupação é o tema, o conteúdo, a coisa, res. Depois vem a dispositio, a segunda fase do processo elaborativo, que representa a ordem ou disposição das ideias e pensamentos encontrados mediante a inuentio. Por fim, na elocutio, terceira fase, as ideias encontradas na inuentio e ordenadas na dispositio são passadas à linguagem, mediante a escolha das palavras e toda sua compositio (regras da boa composição textual).

Dito isso, acrescentemos que o sistema operador da retórica no período clássico é o da inuentio-elocutio, ou seja, vai cuidar igualmente das coisas e das palavras (res e uerba), da produção do conteúdo mediante uma linguagem cuidadosamente produzida. Até o século XVI, tempo em que a concepção da linguagem se definia como interpretatio, as palavras e as coisas ainda não se haviam separado. As coisas tinham primazia sobre as palavras, mas aquelas só poderiam existir fora da mente servindo-se destas.

Podemos entender parte da atuação da inuentio-elocutio ao pensarmos sobre o papel da mímesis na criação literária da Antiguidade. Entre os antigos inexistia a ideia de criatividade artística, no sentido moderno, bem como a ideia de arte enquanto "expressão" da personalidade do artista. Todas as artes eram julgadas pelo nível de trabalho que apresentavam e pela sua eficácia na realização dos propósitos para os quais haviam sido criadas. Não importava a criatividade e/ou a originalidade, mas a habilidade. Importava mais a perfeição, a habilidade, a técnica com que um tema era tratado que ser o primeiro em apresentá- 
lo. A marca pessoal do autor se mostra no estilo. É no estilo que se percebe a apropriação particular de uma matéria pública. Além disso, o texto era considerado aberto. Assim, tomava-se um tema ou uma obra artística pública e se o reapresentava buscando-se frequentemente, mais do que sua imitação, sua emulação, ou seja, a superação do modelo.

Há de se mencionar ainda ao menos dois fatores socioculturais e políticos de grande implicação na prática da tradução entre os romanos: nos tempos áureos de Roma, a sociedade, bilíngue, tinha o grego como segunda língua, aprendida na escola, com preceptores particulares ou mesmo como língua de berço. Some-se a isso o então forte sentimento da Latinitas e o ideal de certos homens, como Cícero, que perseguiam um contínuo aperfeiçoamento da língua e da literatura latinas.

Todos esses elementos acima elencados nos apontam uma direção sobre o modelo de tradução então predominantemente praticado e que aqui chamamos de "suplantação do modelo".

Retomemos as origens da tradução romana. Na Roma mais antiga, por volta do ano 250 a.C., Lívio Andrônico, um poeta romano de origem grega, traduz do grego ao latim a Odisseia, de Homero. Esta tradução constitui a primeira expressão literária, stricto sensu, do mundo romano. A partir daí, vários autores latinos se serviram de modelos gregos seja como fonte para traduções mais ou menos livres, seja como inspiração para suas (re)criações mais ou menos pessoais. A gênese, portanto, da literatura latina e ocidental está na tradução e imitação de modelos gregos. O primeiro período da literatura latina, entre cujos maiores representantes estão Plauto, Terêncio e Catão, é fortemente calcado na transposição e adaptação de modelos gregos à realidade romana, pelo que costumamos chamá-lo de "helenista". Nessa etapa, os romanos se consideravam continuadores dos modelos gregos.

As escolas romanas praticavam um modelo de ensino similar ao das escolas gregas; em ambas a disciplina de gramática compreendia não somente o estudo técnico da linguagem mas também o comentário ou crítica textual, e a disciplina de retórica ensinava como produzir argumentos persuasivos e discursos públicos. A maior diferença entre essas escolas é que na romana a tradução era uma prática comum tanto no aprendizado de gramática como de retórica. Nos estudos gramaticais, era considerada uma forma de comentário textual, e nos de retórica, uma forma de imitação. Daí também a grande superposição entre as práticas de comentários, tradução e imitação literária.

Século I a.C. Duzentos anos depois do surgimento da Odisseia na tradução de Lívio Andrônico, a língua, a literatura, a sociedade romana no todo atinge seu auge. Ainda que tenham constituído sua literatura 
sobre modelos gregos, os romanos não têm uma necessidade imperiosa de traduzir daquela língua, considerando-se que sua sociedade é então bilíngue. Suas traduções revelam antes seu interesse pelas criações literárias, pelos conhecimentos científicos de outros povos e pelo desejo de erigir sua própria literatura. Na tradução artística, uma invenção latina se produz em uma romanização não somente da expressão mas também do conteúdo, com ênfase no texto de chegada. A tradução é, pois, concebida como a produção de uma réplica através da diferença, do deslocamento, da substituição e apropriação cultural ou canônica.

A tradução entre os romanos, analisa Rita Copeland, estava vinculada à teoria e prática da imitação de modelos literários, porém à diferença de outras formas de imitação retórico-literária, a teoria da tradução

Se apresenta como um padrão de transferência, substituição e finalmente deslocamento da fonte. [...] O objetivo da tradução é reinventar a fonte, de modo que, assim como na teoria retórica, a atenção é dirigida para a produção ativa de um novo texto dotado de seus próprios poderes efetivos e adequado às circunstâncias históricas particulares de sua recepção. [...] Esse objetivo tem duas causas: primeiro, a tradução parte de um reconhecimento da diferença; e segundo, a reverência romana pela cultura grega era simplesmente um corolário do desejo de deslocar aquela cultura e eliminar seu poder hegemônico, através da contestação e consequentemente da diferença. ${ }^{2}$

\section{Cícero}

O grande representante romano dessa concepção e prática da tradução é Cícero, apesar de terem nos chegado uns poucos excertos de suas traduções e de ele nos ter legado apenas escassas reflexões dispersas em sua vasta obra sobre seu pensamento em torno à questão da tradução. Dentre esses seus textos, o que fez história foi um opúsculo intitulado De optimo genere oratorum, datado de 46 a.C.

De optimo genere oratorum constitui, assim, a primeira reflexão ocidental sobre a arte e a tarefa do traduzir, apresentada em poucas linhas, na qual seu autor aponta para duas maneiras de traduzir: ut orator, a do "orador", e ut interpres, a do "tradutor":

${ }^{2}$ Cf. Copeland, R. Rhetoric, hermeneutics, and translation in the Middle Ages. Academic traditions and vernacular texts. Cambridge: University Press, 1991, p. 30 (as traduções aqui apresentadas, salvo indicação contrária, são de minha autoria). 
Nec conuerti ut interpres, sed ut orator, sententiis isdem et earum formis tamquam figuris, uerbis ad nostram consuetudinem aptis. In quibus non uerbum pro uerbo necesse habui reddere, sed genus omne uerborum uimque seruaui.

[...] Quorum ego orationes, ut spero, ita expressero uirtutibus utens illorum omnibus, id est sententiis et earum figuris et rerum ordine, uerba persequens eatenus, ut ea non abhorreant a more nostro...

Para Cícero, "traduzir como orador" é conservar os mesmos pensamentos e suas formas e figuras, com palavras adequadas ao costume romano, sem necessidade de traduzir palavra por palavra, mas mantendo o mesmo gênero (qualidade, condição, caráter). O "tradutor", por sua vez - se deduz -, também deveria manter o conteúdo lógico do original e reproduzir com a maior exatidão possível as ideias, as figuras e a ordem expositiva. A diferença entre ambas as atitudes se referiria às palavras. O tradutor traduziria palavra por palavra (uerbum pro uerbo), reproduzindo-as inclusive no mesmo número (adnumerare) em que se encontravam no original.

Embora afirmemos ser Cícero o maior representante da concepção e prática da tradução predominante em sua época, devemos, contudo, cuidar para não tomarmos o orador romano por um preceptista da tradução, defensor da tradução fundada sobre uma apreensão global do sentido em oposição a uma tradução mais literal. Esta reflexão de Cícero, De optimo genere oratorum, foi apresentada como um prefácio à tradução de dois discursos, opostos entre si, de Ésquines e de Demóstenes; não em um tratado específico de tradução, mas em um tratado de eloquência, sobre um gênero, a imitação, no qual o próprio autor assinala não ter realizado um trabalho de tradutor mas um tipo de imitação. O objeto é, pois, a aquisição da eloquência através da imitação de oradores gregos. Nesse tratado, Cícero esclarece seu procedimento em relação ao texto original, mas não estabelece regras para a tradução.

${ }^{3}$ Cícero, De optimo genere oratorum V, 14 e VII, 23: "Não traduzi como tradutor, mas como orador, com os mesmos pensamentos e suas formas bem como com suas figuras, com palavras adequadas ao nosso costume. Para tanto não tive necessidade de traduzir palavra por palavra, mas mantive o gênero das palavras e sua força. Não considerei, pois, ser mister enumerá-las ao leitor, mas como que pesá-las. (...) Se, como espero, eu tiver assim reproduzido os discursos dos dois servindo-me de todos os seus valores, isto é, com os pensamentos e suas figuras e na ordem das coisas, buscando as palavras até o ponto em que elas não se distanciem de nosso uso...” 
Depreende-se, sim, daquela exposição, que sua tradução é do tipo retórica, imitativa, podendo ser definida como imitatio ou aemulatio. Ao não traduzir "palavra por palavra" mas buscando manter "o gênero das palavras e sua força, com os mesmos pensamentos e suas formas bem como com suas figuras, com palavras adequadas ao nosso costume", a preocupação de Cícero volta-se prioritariamente não ao texto fonte, mas à língua de chegada: trata-se de reconstituir o texto verbal e estilisticamente representar um ato de ressignificação. Todos os elementos do texto, forma e estilo, dependem da interpretação, são adaptados "ao nosso costume", transplantados, naturalizados, transferidos ao sistema do latim corrente. Sua tradução é reelaboração, é reinvenção da fonte grega, é apropriação, latinização. Cícero suplanta retoricamente o original.

Da reflexão ciceroniana sobre sua prática como tradutor, podemos inferir que havia dois modos distintos de tradução: ut interpres e ut orator. O fato de Cícero confessar ter traduzido ut orator não significa que devamos entender a tradução ut interpres como sendo indigna ou que seu tipo de literalismo implique ininteligibilidade. Vt interpres seria antes uma tradução gramatical, não retórica, que cuida da correção da mensagem, mas sem arte, com o objetivo de exercitar, entender ou esclarecer língua e texto, nos moldes do que se fazia na escola ao se estudar a gramática. Vt orator, por outro lado, seria a tradução retóricoliterária, que atentava sobremodo para a língua de chegada e para a produção de enunciados, a que produziria ao fim e ao cabo arte literária, literatura.

São Jerônimo, em sua epístola Ad Pammachium de optimo genere interpretandi (ca.395), comenta o tipo de tradução praticado por Cícero:

Quanta in illis [Cicero] praetermiserit, quanta addiderit, quanta mutaverit, ut proprietates alterius linguae suis proprietatibus explicaret....

A conclusão é que Cícero traduziu seus "modelos" com um grande desejo de configuração literária, o que se vincula fortemente ao então conceito literário de aemulatio como reprodução competitiva.

A concepção e prática de Cícero, depreendidas de seu texto, revelam um método e uma finalidade que se assemelham às traduções

${ }^{4}$ Jerônimo, Ad Pammachium de optimo genere interpretandi V, 2: "Todas as omissões, acréscimos e mudanças que (Cícero) introduziu nessas traduções com o objetivo de trasladar as expressões próprias da outra língua servindo-se daquelas da sua." 
que se produziam comumente do grego, como podemos perceber através de outros textos latinos.

Em uma das passagens de sua Institutio oratoria (X, 5-2-5) que abordam o tema da tradução, Quintiliano expõe a prática da tradução como um exercício retórico, que deve se servir desta arte e competir com seu modelo; e comenta que, desta forma, Cícero traduziu Platão e Xenofonte:

Vertere Graeca in Latinum ueteres nostri oratores optimum iudicabant.

Et ipsis sententiis adicere licet oratorium robur, et omissa supplere, effusa substringere. ${ }^{6}$

Circa eosdem sensus certamen atque aemulationem. ${ }^{7}$

Id Cicero sua ipse persona frequentissime praecepit, quin etiam libros Platonis atque Xenophontis edidit hoc genere tralatos. ${ }^{8}$

Também Plínio o Jovem, ca. 100 a.C., em uma carta a Fusco (VII, 9), apresenta a tradução como um exercício de retórica, no qual o modo de traduzir que se praticava consistia predominantemente em paráfrases e imitação:

Vtile in primis, et multi praeceperunt, uel ex Graeco in Latinum uel ex Latino uertere in Graecum; quo genere exercitationis proprietas splendorque uerborum, copia figurarum, uis explicandi, praeterea imitatione optimorum similia inueniendi facultas paratur. Simul quae legentem fefellissent transferentem fugere non possunt. ${ }^{9}$

\footnotetext{
${ }^{5}$ Quintiliano, Institutio oratoria X, 5, 2: “Traduzir do grego ao latim era, na concepção de nossos antigos oradores, o melhor exercício."

${ }^{6}$ Quintiliano, Institutio oratoria X, 5, 4: "Aos pensamentos mesmos pode-se acrescentar a força oratória, suprir os incompletos, encurtar os extensos."

${ }^{7}$ Quintiliano, Institutio oratoria X, 5, 5: "Em torno aos mesmos pensamentos haja luta e emulação."

${ }^{8}$ Quintiliano, Institutio oratoria X, 5, 5: “Isto aconselha frequentemente o próprio Cícero em pessoa, que também publicou os livros de Platão e Xenofonte traduzidos desta maneira."

${ }^{9}$ Plínio, Epistulae VII, 9: "Antes de tudo é útil, e muitos recomendaram traduzir seja do grego ao latim seja do latim ao grego; porque com este tipo de exercício se procura a propriedade e o resplendor das palavras, a riqueza das figuras, os métodos para ampliar e, além disso, a faculdade para criar de maneira similar a partir da imitação dos melhores. Ao mesmo tempo, o que haja falhado ao leitor não pode escapar ao tradutor."
} 


\section{Horácio}

Ao estudarmos a tradução entre os romanos, além de Cícero encontramos frequentemente o nome de Horácio. E vale a pena lembrarmo-nos aqui do insigne poeta, ainda que seja para desfazer um equívoco histórico.

Cerca de trinta anos depois do comentário de Cícero sobre a tradução, Horácio publica a Epistula ad Pisones, ca. 13 a.C., sobre problemas relativos à estética literária, à criação poética e que, por seu conteúdo essencialmente teórico, é tratada como um "texto científico" pouco tempo depois de seu surgimento e nomeada por Quintiliano em sua Institutio oratoria (I, 8, 3) com o título de Liber de arte poetica. Nesse texto, Horácio trata basicamente do teatro, sendo um de seus principais postulados o de que a criação poética é uma imitação e sua finalidade é a representação teatral. ${ }^{11}$

Ao lado do texto de Cícero, os versos 133-134 da Ars poetica fizeram história no universo da tradução e foram interpretados e utilizados tanto pelos defensores da tradução livre como pelos da literal: "Nec uerbum uerbo curabis reddere fidus/ Interpres."

Contudo, ao menos desde o século XVI - veja-se, por exemplo, Jacques Peletier, o capítulo Des traductions de sua Art poétique (1555) -, alguns estudiosos chamam a atenção para um equívoco na interpretação dos versos horacianos que persiste até nossos dias. Ao escrever esses versos, o poeta romano não se dirigia a tradutores mas a escritores, aconselhando-lhes buscarem originalidade não no que dizem, mas na maneira de dizê-lo. O "tradutor" é um elemento de comparação: o escritor, ao tratar um assunto conhecido, não deve fazê-lo servindo-se das mesmas palavras de sua fonte, pois isso é o que faria um "tradutor fiel”. Horácio não estava dando preceitos para a tradução. A interpretação errônea parte da descontextualização dos versos. Basta que se considere alguns versos anteriores para chegar a outra conclusão:

\footnotetext{
${ }^{10}$ Cf. Schäffer, E. Nachwort. In: Horaz. Ars poetica - Die Dichtkunst. Stuttgart: Reclam, 1989, p. 56.

${ }^{11}$ Cf. Grimal, P. Essai surl' Art Poétique d'Horace. Paris: Sedes, 1968, p. 38.

${ }^{12}$ Horácio, Ars poetica 133-134: "Nem cuidarás de reproduzir palavra por palavra qual fiel Tradutor."
} 
Difficile est proprie communia dicere; tuque rectius Iliacum carmen deducis in actus quam si proferres ignota indictaque primus. Publica materies priuati iuris erit, si non circa uilem patulumque moraberis orbem, nec uerbo uerbum curabis reddere fidus interpres nec desilies imitator in artum, unde pedem proferre pudor uetet aut operis lex..$^{13}$

Da época dos romanos, cuja literatura nasce da tradução, sabe-se que houve as atividades tradutora e literária que, entremescladas, produziram o que hoje se conhece como a literatura romana. Não obstante, os poucos registros de reflexões sobre a prática da tradução nesse período não foram escritos com o propósito de investigar o tema em si ou de oferecer preceitos sobre a melhor maneira de traduzir, mas se encontram de forma quase casual em textos que tratam de outras questões. Dois dos maiores escritores romanos, Cícero e Horácio, que têm sido citados durante séculos sobretudo em defesa da tradução livre, não foram preceptistas da tradução. Contudo, esses parcos testemunhos do passado dão a conhecer a clara existência de ao menos duas formas de tradução praticadas entre eles, a tradução palavra por palavra e a tradução parafrástica, criativa ou retórica; ou, em outros termos, a tradução gramatical e a retórica. Dada a existência do bilinguismo ou inclusive trilinguismo da sociedade romana e admitida sua visão de tradução como produção literária, afirma Susan Bassnett que a arte tradutora ali praticada foi única no gênero: o leitor romano podia considerar a tradução um metatexto em relação com o original, e o tradutor romano, que era julgado por sua habilidade em usar criativamente seu modelo, podia conceber a tarefa da tradução como exercício de estilística comparada. ${ }^{14}$

\footnotetext{
${ }^{13}$ Horácio, Ars poetica, v. 128-135: "É difícil contar, com propriedade, coisas popularizadas. Tu, porém, podes pôr em cena um canto ilíaco mais convenientemente do que se mostrasses pela primeira vez coisas desconhecidas e inéditas. Matéria pública será de direito privado, se não delirares em torno de um ponto desprezível e banal, nem fiel tradutor tratares de repor palavra por palavra, nem imitador te lançares numa situação embaraçosa, de onde a timidez ou a estrutura da obra não permita sair."

${ }^{14}$ Bassnett-Guire, S. Translations studies. New York: Methuen \& Co., 1980, p. 45.
} 


\section{Referências}

BASSNETT-GUIRE, S. Translations studies. New York: Methuen \& Co., 1980.

CICERÓN. De optimo genere oratorum. In: LAFARGA, F. (Ed.). El discurso sobre la traducción en la historia. Antología bilingüe. Barcelona: EUB, 1996, p. 32-44.

COPELAND, R. Rhetoric, hermeneutics, and translation in the Middle Ages. Academic traditions and vernacular texts. Cambridge: University Press, 1991.

FURLAN, M. A tradução retórica do Renascimento. In: FURLAN, M. (Org.). Clássicos da teoria da tradução. Antologia bilingue. Vol. 4, Renascimento. Florianópolis: NUPLITT, 2006, p. 17-45.

GRIMAL, P. Essai surl' “Art Poétique” d'Horace. Paris: Sedes, 1968.

HORACE. Satires, Epistles and Ars poetica. With an English translation by H. Rushton Fairclough. Cambridge, Mass./ London: Harvard University Press, 1961.

PLINE LE JEUNE. Epistulae. Texte établi et traduit par A.-M. Guillemin. Paris: Les Belles Lettres, 1928. Tome III, livres VII-IX.

QUINTILIAN. Institutio oratoria. Texte établi et traduit par J. Cousin. Paris: Les Belles Lettres, 1979. Tome VI, livres X, XI.

SAN JERÓNIMO. Epistula LVII ad Pammachium. Liber de optimo genere interpretandi. In: LAFARGA, F. (Ed.). El discurso sobre la traducción en la historia. Antología bilingüe. Barcelona: EUB, 1996, p. 46-71.

SCHÄFFER, E. Nachwort. In: Horaz.Ars poetica - Die Dichtkunst. Stuttgart: Reclam, 1989, p. 55-67. 